\title{
EL PRINCIPIO DISPOSITIVO EN EL ESTADO AUTONÓMICO*
}

\author{
POR \\ ENRIC FOSSAS ESPADALER \\ Profesor Titular de Derecho Constitucional (UAB) \\ Catedrático habilitado de Derecho Constitucional \\ Letrado del Tribunal Constitucional
}

\section{INTRODUCCIÓN}

Este trabajo tiene por objeto el estudio del llamado principio dispositivo como principio estructural que establece la Constitución de 1978 (CE) al regular la organización territorial del poder político.

La elección del tema se justifica en una doble circunstancia. La primera es que siendo comúnmente admitido que dicho principio constituye la característica más destacada de nuestra Constitución, que la distingue de todas las demás del mundo, hasta el punto de ser considerado la más original aportación de los constituyentes de 1978 al constitucionalismo universal, no ha sido objeto de especial atención entre los estudiosos de nuestro país. El principal propósito del trabajo es pues contribuir al análisis de esta singularidad que incorpora nuestro ordenamiento constitucional, intentando paliar la escasez de reflexiones sobre el principio dispositivo que, al menos hasta hoy, se constata en nuestra literatura iuspublicista.

La segunda circunstancia que justifica el presente trabajo es la estrecha relación del tema tratado con la actual realidad constitucional española. Por una par-

* La versión íntegra de este trabajo se encuentra en la obra ENRIC FOSSAS ESPADALER, El principio dispositivo en el Estado Autonómico, Marcial Pons-IVAP, Madrid-Barcelona- Buenos Aires, 2007, 195 págs. 
te, el proceso de reformas estatutarias iniciado con la elaboración y aprobación del nuevo Estatuto de Autonomía de Cataluña de 2006 ha suscitado un vivo debate político y académico sobre los límites materiales y procesales de la reforma estatutaria para configurar el autogobierno de cada Comunidad Autónoma, e incidir directa o indirectamente sobre la organización territorial en su conjunto sin necesidad de modificar la Constitución. De este modo, aunque sin mencionarlo, se plantea cuál es la vigencia y el alcance del principio dispositivo en la fase actual de desarrollo del Estado de las Autonomías, y se discute la oportunidad política de mantenerlo indefinidamente en nuestra Constitución, aunque sea de forma latente.

Por otra parte, tras las elecciones de 14 de marzo de 2004 el Presidente del Gobierno anunció en su discurso de investidura una reforma constitucional sobre cuatro puntos, señalando que se solicitaría un informe sobre la misma al Consejo de Estado. Uno de esos puntos es la incorporación a la Constitución de la denominación oficial de las diecisiete Comunidades Autónomas y las dos Ciudades Autónomas, extremo aparentemente intrascendente pero que el Gobierno, y posteriormente el Informe del Consejo de Estado, vinculan a una "superación de la apertura inicial del modelo" y en consecuencia, a una posible reducción o eliminación del principio dispositivo.

El tema del que trata este ejercicio se encuentra pues en el centro del proceso de reformas normativas sobre la organización territorial del Estado en el que hoy vive inmerso nuestro sistema constitucional, y que previsiblemente continuará en los próximos años.

El planteamiento de este trabajo, sintéticamente, se basa en los cuatro puntos siguientes:

1) El principio dispositivo es un principio estructural básico de nuestra Constitución referido a la organización territorial del poder, uno de los principios constitucionales cardinales y probablemente la característica más singular de la CE. Su incorporación al texto constitucional fue una "opción consciente» adoptada en el proceso constituyente, fruto del consenso, e inspirada en la Constitución de 1931. Su esencia consiste en atribuir a las entidades territoriales a las que se reconoce el derecho a la autonomía (art. 2 CE) una capacidad decisiva en la configuración de la organización territorial, que la misma Constitución no habría llevado a cabo, pues habría remitido esta operación a unos poderes constituidos mediante su «desconstitucionalización» parcial, introduciendo así una apertura en aquella organización, que de este modo se ve sometida a permanente discusión y definición desde la aprobación del texto constitucional. 
2) El principio dispositivo no es propiamente la causa de esta singular forma de indefinición constitucional-territorial porque no responde a la pregunta ¿dónde se precisa el consenso para decidir? si no ¿quién debe participar en el consenso para decidir? La respuesta a la primera pregunta se encuentra en el la desconstitucionalización, es decir, en el compromiso constitucional «apócrifo» schmittiano: la decisión política no se adopta en el texto constitucional sino que se aplaza a un momento postconstitucional y se traduce en normas formalmente infraconstitucionales. La respuesta a la segunda pregunta sí se encuentra en el principio dispositivo: la decisión política debe adoptarse por los representantes de los territorios que primero aspiran a y luego disponen de autonomía, conjuntamente con las instituciones representativas del Estado. De ahí que en la fase de instauración de una nueva forma territorial del Estado español, el principio confería una capacidad decisiva para la concreta configuración de la nueva organización del Estado que la Constitución habilitaba. En concreto, en dos elementos esenciales de la estructura territorial: la delimitación de las entidades territoriales que ostentarían una parte del poder estatal (CCAA), y la determinación de ese poder, cuestiones que se convierten en materias que deben contener el Estatuto de Autonomía (EA) de cada una, como norma institucional básica (art. $147 \mathrm{CE}$ ).

En las fases posteriores, una vez instaurado un cierto modelo de descentralización territorial (fase de modificación), el principio dispositivo permite que sean las Comunidades Autónomas ya constituidas quienes puedan proponer y pactar la modificación de aquellos elementos definidores de su autonomía mediante la reforma de sus respectivos Estatutos de Autonomía.

En ambos momentos, instauración y modificación, el principio dispositivo atribuye la facultad de impulso y confiere la capacidad de codecisión a los representantes de unos territorios (primero indefinidos, después Comunidades Autónomas), dejando así parcialmente en sus manos el cierre y la reapertura del modelo de organización territorial del poder, lo cual introduce en el mismo un elemento de indeterminación e inestabilidad.

3) Desde la entrada en vigor de nuestra Constitución se han intentado combatir los efectos «distorsionadores» o «disfuncionales» del principio dispositivo, pero sin enfrentarse a la desconstitucionalización. Como es conocido, se trató de reducir su alcance a través de mecanismos de naturaleza diversa (una supuesta convención constitucional en 1981, la frustrada LOAPA, los pactos autonómicos de 1992 y su traducción jurídica) destinados a dirigir el proceso de descentralización política desde las instancias centrales con el propósito de «cerrar el modelo» o "ultimar» el Título VIII mediante el acuerdo entre las dos grandes fuerzas políticas de ámbito estatal y no desde la iniciativa de las instan- 
cias territoriales. Ello entrañó una disminución de la eficacia del principio dispositivo en la construcción de dicho modelo, a menudo forzando el propio texto constitucional.

Sin embargo, el proceso autonómico habría demostrado que el principio dispositivo no pudo eliminarse completamente a través de ninguno de los instrumentos señalados, y sigue manteniéndose aún latente, posibilitando la revisión de determinados aspectos de la organización territorial, esencialmente a través de las reformas de los Estatutos de Autonomía, cuyos procedimientos, a pesar de su rigidez, pueden ser activados por cualquier Comunidad Autónoma con el fin de proponer y pactar la modificación de algunos elementos que definen su autonomía, pero que pueden afectar también al conjunto del sistema. Esta posibilidad, que la desconstitucionalización mantiene abierta indefinidamente, no ha generado grandes problemas porque las numerosas reformas estatutarias realizadas hasta hoy han sido resultado del acuerdo entre los dos grandes partidos estatales. Tales reformas se han llevado a cabo en la mayoría de Comunidades Autónomas, pero no en el País Vasco y Cataluña, que han mantenido intactos hasta 2006 sus Estatutos de Autonomía originales.

Pues bien, las reformas estatutarias emprendidas en esas dos Comunidades Autónomas, a pesar de su disparidad, han puesto en evidencia la virtualidad del principio dispositivo y la imposibilidad de lograr su neutralización sin abordar la desconstitucionalización. En puridad, ha sido el nuevo Estatuto de Autonomía de Cataluña el que ha suscitado esta cuestión porque después de su larga tramitación fue finalmente aprobado por las Cortes Generales y ya ha sido en parte imitado por otras Comunidades Autónomas, lo que no ha ocurrido con el llamado Estatuto político del País Vasco, que ni siquiera pasó el trámite de la toma en consideración.

Por otra parte, el Gobierno surgido de las elecciones generales de 2004 lanzó una propuesta de reforma constitucional sobre cuatro puntos, señalando que se solicitaría un informe sobre la misma al Consejo de Estado. Uno de esos puntos es la incorporación a la Constitución de la denominación oficial de las diecisiete Comunidades Autónomas y las dos Ciudades Autónomas, extremo aparentemente intrascendente pero que el mismo Gobierno, y posteriormente el Informe del Consejo de Estado, vinculan a una «superación de la apertura inicial del modelo» y en consecuencia, a una posible reducción o eliminación del principio dispositivo.

4) La sucesión cronológica de las mencionadas reformas institucionales ha conducido a que la propuesta de reforma constitucional se haya situado después de las reformas estatutarias, y de ahí que en la discusión de aquélla se haya suscitado por primera vez la posibilidad de reducir o eliminar el principio disposi- 
tivo de nuestra Constitución poniendo fin a la desconstitucionalización. De esta forma, probablemente invirtiendo el orden lógico, el debate sobre las reformas estatutarias ha conducido al debate sobre la reforma constitucional del Estado Autonómico. Ello se habría producido de manera casi imprevista pues la propuesta del Gobierno no tenía, al menos explícitamente, tal propósito. El documento sobre la reforma constitucional remitido por el Gobierno al Consejo de Estado señala que «ninguna de ellas [refiriéndose a las cuatro modificaciones constitucionales propuestas] pretende rectificar o invertir el núcleo de las decisiones adoptadas en su día por el constituyente», si bien la propuesta relativa a la denominación constitucional de las Comunidades Autónomas «significa superar la apertura inicial del modelo de descentralización política establecido por el constituyente». Por su parte, en respuesta al encargo del Gobierno, el Informe del Consejo de Estado afirma: «Esta voluntad expresa de consolidar un "modelo propio de descentralización política" implica sin duda una matización importante del objetivo de "superar la apertura inicial" de dicho modelo, pues la característica más destacada de este modelo ha sido la de permanecer abierto a impulsos del principio dispositivo" (..), aclarando que una eventual reforma destinada a abandonar el principio dispositivo no tendría el propósito de "superar" la apertura inicial del sistema sino el de «sustituir por otro el sistema abierto que hoy tenemos (...)». De este modo, la iniciativa de reforma constitucional puede ser entendida, según Rubio Llorente, como una respuesta a la necesidad de reflexionar sobre el significado del principio dispositivo tras veinticinco años de operación. En realidad, la propuesta de reforma constitucional deja planteada por primera vez la posibilidad de reducir o eliminar el principio dispositivo mediante una modificación del texto constitucional.

El objetivo de este trabajo es precisamente reflexionar sobre esta posibilidad, lo que exige entrar en un terreno más especulativo y propositivo que interpretativo, tarea que creo que también nos incumbe a los juristas.

\section{LA INCORPORACIÓN DEL PRINCIPIO DISPOSITIVO A LA CONSTITUCIÓN DE 1978 Y EL PRECEDENTE DE LA II REPÚBLICA}

El principio dispositivo tiene una doble procedencia: la experiencia constitucional de la II República, que habría ejercido una influencia decisiva en los trabajos constituyentes; y el consenso como método de elaboración de la Constitución de 1978, así como las circunstancias de la transición política.

En el debate constituyente de 1931 están ya presentes las ideas de desconstitucionalización y principio dispositivo, aunque no con estos nombres. El re- 
sultado fue la adopción de una singular forma de organización llamada «Estado integral», expresión que designaba un tertium genus entre los conceptos de Estado unitario y Estado Federal, y cuya procedencia doctrinal debe buscarse en la influencia que ejercieron sobre algunos profesores españoles notables juristas alemanes de los años treinta, especialmente la teoría de la integración de Smend. El Profesor Trujillo ha señalado que en esa forma estatal novedosa se asigna una amplia intervención al principio dispositivo, al que califica de «fundamental principio estructurador del Estado integral». Su justificación explícita en los trabajos constituyentes era que en función de la diversa intensidad de las demandas autonómicas, el Estado podía dar cabida a diversos grados de autonomía territorial o incluso a provincias que no se organizaran como Regiones autónomas; pero existió además un propósito no expresado de alcanzar una descentralización que por consentida o consensuada, no pudiera tacharse de otorgada.

Detrás de la adopción de este diseño institucional se encontraban dos cuestiones vinculadas entre sí:

1) La generalización o no de la autonomía. En este punto el principio dispositivo resume la fórmula para evitar tanto la generalización de la autonomía a todos los territorios como la concesión excepcional de una autonomía particular sólo a algunos por parte de la Constitución.

2) La situación política del momento, en particular, el Pacto de San Sebastián, que se basaba en el reconocimiento del derecho a la autodeterminación interna de Cataluña, y la aprobación por éste de su Estatuto de Cataluña antes de aprobarse la Constitución republicana. Aunque sería discutible, podría entenderse que el modelo de 1931 fue el fruto de compromisos adquiridos para permitir a Cataluña principalmente decidir dentro de un marco constitucional ideado para dejar un margen dispositivo grande a la región autónoma. En tal disponibilidad, según Muñoz Machado, radicaba el ejercicio de la autodeterminación interna, y a esa manera de resolver la organización y los poderes propios del territorio autónomo empezamos a llamarlo a partir de 1978 «principio dispositivo", es decir, una facultad de decidir sobre el autogobierno y sus instituciones acotada por los principios genéricos de la Constitución.

El esquema conceptual de la Constitución de 1931, aunque con diferencias notables, se trasladó después a la Constitución de 1978. Desde el anteproyecto de Constitución se opta por un modelo abierto basado en el principio dispositivo tanto para constituirse en territorio autónomo como para la asunción de competencias. Ese "modelo abierto", concebido en la misma Ponencia, va a mantenerse a lo largo del proceso de tramitación parlamentaria debido a la incapacidad de los constituyentes para llegar a un acuerdo sobre un modelo con- 
creto, pero sobretodo a la ausencia de un debate general sobre la estructura del Estado, que se concentró esencialmente en la «cuestión nacional».

El resultado final, fruto del consenso, fue la adopción de un compromiso constitucional «apócrifo», en términos schmittianos, que consagra la desconstitucionalización, y la incorporación del principio dispositivo inspirado en la Constitución de 1931.

El esquema territorial se aproxima al de la de la II República, pero con una diferencia sustancial: en el proceso constituyente de 1931 el principio dispositivo se introdujo como una fórmula para evitar tanto la generalización de la autonomía a todos los territorios como la concesión excepcional de una autonomía particular sólo a algunos En cambio, en el proceso constituyente de 1978 el principio dispositivo fue esencialmente la fórmula para evitar que la previsible generalización de la autonomía a todo el territorio (ya instaurada con las preautonomías) impidiera la diferenciación entre Comunidades Autónomas, pero tampoco se cerrara el paso a su futura igualación mediante las reformas estatutarias.

Los debates constituyentes ponen de manifiesto que la estructura territorial del Estado no fue objeto, como en 1931, de una discusión política y jurídica profunda porque desde los mismos inicios del iter constituyente existió ya un consenso sobre la indeterminación del modelo territorial, y también demuestran que, sin mencionarlo explícitamente, el principio dispositivo fue una "opción consciente» de las Cortes Constituyentes, que atribuyeron a la voluntad de las «nacionalidades y regiones» un papel decisivo en el proceso de construcción de un nuevo modelo de organización territorial. El constituyente alcanzó ese compromiso constitucional «apócrifo» sin adoptar una «decisión constitucional fundamental» sobre la estructura territorial, pero sí incorporó el principio dispositivo como principio estructural básico sobre el cual aquélla debía desarrollarse.

\section{PRINCIPIO DISPOSITIVO Y DESCONSTITUCIONALIZACIÓN}

Uno de los argumentos centrales de este trabajo se basa en la distinción entre desconstitucionalización y principio dispositivo ya que a mi juicio existe en la literatura iuspublicista una cierta confusión entre dos conceptos que deben distinguirse.

Debe distingue claramente entre la desconstitucionalización, como entrega del modelo de organización territorial al legislador no constituyente, aunque éste fuera sólo el legislador estatal; y lo que es propiamente el contenido del principio dispositivo*: la creación de la nueva organización del Estado que la Consti- 
tución no lleva a cabo, no se deja sólo en manos del legislador no constituyente estatal ya que se precisa de la capacidad decisiva de las entidades territoriales para la concreta configuración de esa organización que el constituyente ha renunciado a crear.

La distinción, y por tanto, la separación de estos dos conceptos, no implica negar su íntima relación en el sistema autonómico. En un plano teórico, podría imaginarse la existencia de sistemas territoriales en los cuales estuvieran presentes sólo uno de ellos. Se podría pensar en un sistema con desconstitucionalización sin principio dispositivo, mediante la remisión al legislador no constituyente estatal. Más difícil es imaginar una organización territorial regida por el principio dispositivo pero sin desconstitucionalización. Quizás algunos sistemas en los que la Constitución prevé un régimen de autonomía sólo para algunas partes del territorio (Portugal), o un régimen especial para algunas de las entidades territoriales (Regiones italianas de Estatuto especial), o las Constituciones de las Provincias canadienses.

Más allá de estas especulaciones teóricas, lo cierto es que tanto en el Estado integral de la II República como en el Estado autonómico, desconstitucionalización y principio dispositivo se encuentran estrechamente vinculados porque en ambos la primera se pone constitucionalmente al servicio del segundo, aunque con fines distintos. En los inicios del Estado Autonómico la desconstitucionalización no ha estado al servicio del principio dispositivo sino que ha sido utilizada para intentar su neutralización, sin lograr su eliminación; posteriormente, la desconstitucionalización ha sido aprovechada para ampliar al máximo la eficacia del principio dispositivo, y por ello la cuestión decisiva de las reformas estatutarias es precisamente los límites de esa libre disposición.

El concepto de desconstitucionalización en el contexto del debate autonómico español sugiere un ejercicio singular del poder constituyente, que renuncia a adoptar decisiones políticas traducidas en determinaciones constitucionales y difiere al legislador posconstitucional una decisión que le correspondería a él mismo. La idea originaria de desconstitucionalización en el debate autonómico español se debe al conocido artículo de Cruz Villalón en el que el autor afirmaba que la Constitución habría "operado una desconstitucionalización de la estructura del Estado», la cual se traducía "en una simple reserva de ley orgánica». Sin embargo, el mismo autor precisó con posterioridad que «Desconstitucionalizar no era remitirse al legislador ordinario, sino a un legislador de características únicas. La desconstitucionalización, en una palabra, se producía junto a una reserva de Estatuto».

La doctrina ha expresado la vinculación entre desconstitucionalización y ejercicio del poder constituyente. Se ha afirmado, por ejemplo, que la opción acep- 
tada para la reforma de los Estatutos resultantes de los primeros Pactos autonómicos fue una opción constituyente (Rubio Llorente). O que el ejercicio del poder estatutario significa que el poder constituyente originario acepta una fragmentación, al entregar parte de las regulaciones que le competen a un poder subordinado (Muñoz Machado). Se ha distinguido incluso entre un proceso "constituyente primario", que se cerró con la promulgación de la Constitución, y un proceso "constituyente secundario", que se prolongó hasta que se aprobaron los Estatutos de Autonomía (Aragón). Y se ha afirmado que la estructura del Estado español es consecuencia de dos procesos: un proceso constituyente que culmina en 1978, en el que no se define la estructura del Estado, pero se posibilita su definición; y un proceso estatuyente, que se inicia en 1979 y culmina en 1983, a través del cual acaba quedando definida la estructura del Estado «dentro de las posibilidades y límites previstos en la Constitución» (Pérez Royo).

Junto a la anterior distinción, debe distinguirse entre desconstitucionalización formal y material. La desconstitucionalización formal significa que la adopción de decisiones políticas de alcance materialmente constitucional no se lleva a cabo directamente a través del procedimiento con el cual se ha elaborado $\mathrm{y}$ aprobado el texto constitucional, que normalmente exige unas elecciones constituyentes, mayorías cualificadas e incluso la ratificación del cuerpo electoral, sino que mediante una fórmula dilatoria se remiten aquellas decisiones a un procedimiento legislativo en el que son determinantes las mayorías políticas coyunturales surgidas de las elecciones parlamentarias ordinarias. Esta remisión se hace en favor de los EEAA, cuyo procedimiento de reforma adquiere así especial importancia. Los constituyentes optaron por configurar la reforma estatutaria en términos muy generales y, al contrario de la Constitución de 1931, ponerla a disposición de todas las Comunidades Autónomas, que la regulan en su respectivo Estatuto de Autonomía (art. 147.3 CE) dentro de los límites de la Constitución. El procedimiento de reforma estatutaria adoptado en los Estatutos, más allá de las especialidades, otorga el monopolio de iniciativa a los respectivos Parlamentos territoriales, convirtiendo a aquéllos en una suerte de leyes constitucionales secundarias, inmodificables unilateralmente tanto por el Estado como por la Comunidad Autónoma, pasado a formar parte del «bloque constitucional»(Aragón).

La desconstitucionalización material se refiere a la estructura del Estado, es decir, a la estructura territorial del poder político. Lo más destacable del alcance material de la desconstitucionalización es que la Constitución no contenga dos de los elementos esenciales en las estructuras basadas en la división territorial del poder entre entidades centrales o generales y entidades territoriales subestatales: 
la determinación de esas entidades territoriales entre las que se distribuye el poder, y los términos de esa distribución, que se traduce en un sistema constitucional de reparto de competencias. Pero al igual que sucede con la desconstitucionalización formal, la desconstitucionalización material no es una cuestión que se plantee en términos de todo o nada sino que se trata también de una cuestión de grado. Por ello no puede afirmarse que en el ordenamiento español la estructura territorial se encuentre totalmente desconstitucionalizada, aunque ello no permite negar su existencia.

Finalmente, debe hacerse una referencia a las preautonomías, que no son propiamente una forma de desconstitucionalización pero sí tuvieron un efecto desconstitucionalizador sobre uno de los elementos de la estructura territorial: la fijación del mapa autonómico y la delimitación del territorio de cada entidad. Se ha señalado en este sentido que con las preautonomías se cerró el debate sobre uno de los elementos sustanciales a la forma territorial, lo cual supuso un «hurto a la actividad del poder constituyente y al propio diseño constitucional» (García Roca); y se ha considerado a las preautonomías una «opción paraconstitucional (...) calificada de proceso constituyente implícito (...) al margen de la opción constituyente e incluso contraviniendo a la misma» (Herrero de Miñón).

Ello queda reflejado en la Disposición Tansitoria Primera CE: en los territorios dotados de un régimen provisional de autonomía, sus órganos colegiados superiores podrán sustituir la iniciativa el art. 143.2 CE, lo que ocurrió realmente. Los Acuerdos autonómicos de 1981 convirtieron en definitivo la casi totalidad del mapa preconstitucional con la aprobación de los respectivos Estatutos de las 17 CCAA actuales, superados algunos problemas surgidos en la configuración de la Comunidad Autónoma de Castilla-León.

\section{EL PRINCIPIO DISPOSITIVO COMO PRINCIPIO CONSTITUCIONAL}

Existe un notable acuerdo entre los constitucionalistas españoles en que el principio dispositivo constituye la característica más destacada de la Constitución de 1978.

El principio ha sido designado con distintos nombres (principio de «voluntariedad», de "voluntariedad limitada», principio de "voluntariedad autonómica»; incluso se ha distinguido entre principio "potestativo» y principio "dispositivo») pero la doctrina siempre le atribuye el carácter de principio, y más concretamente el de principio constitucional, hasta ser calificado como «uno de los principios cardinales de nuestra Constitución» (Rubio Llorente). 
El principio dispositivo encajaría en la categoría de principio constitucional o principio general del Derecho de carácter constitucional, en el sentido que le atribuye Garrorena cuando sostiene que buena parte de la teoría de los principios constitucionales hay que remitirla a la teoría común de los principios generales del Derecho, entendidos como «enunciados normativos muy genéricos que expresan convicciones jurídicas básicas en las que quedan sintetizados determinados modos fundamentales de ser del Derecho». Se trata de un principio que se encuentra positivizado en el texto constitucional, tal como ha reconocido el Tribunal Constitucional (STC 16/1984, de 6 febrero, FJ 2), y se manifiesta en numerosos preceptos que consagran el valor enunciado en el mismo. En tanto que principio general del Derecho, el principio dispositivo desempeña una función informadora de otras normas, mientras que como principio constitucional goza de la fuerza normativa de la Constitución, y por ello es de preferente aplicación a cualquier norma jurídica que lo contradiga, cualquiera que sea el rango de ésta.

Por otra parte, el principio dispositivo se ha considerado «el principio estructural básico de nuestra Constitución en cuanto a la organización territorial del poder» (Rubio Llorente) y de ello se derivarían a mi juicio dos consecuencias:

La primera es que no puede concebirse exclusivamente en términos procesales sino que tiene un indudable aspecto material pues afecta a la misma definición de la forma de Estado al conformar una manera de ser el poder estatal desde el punto de vista territorial. El principio obliga a que los elementos esenciales que definen la estructura del Estado sean decididos y modificados con la voluntad y la participación de los sujetos territoriales, y es en este sentido que puede decirse que constituye un principio estructural en cuanto a la organización territorial.

La segunda consecuencia deriva de su carácter de principio estructural «básico», y se concreta en la "modulación» que opera respecto de los dos principios básicos que contiene la Constitución sobre la organización territorial: unidad y autonomía.

En relación al principio de unidad, el principio dispositivo comporta que el poder constituyente originario acepta una fragmentación, entregando parte de las regulaciones que le competen a un concreto poder subordinado, de tal forma que el poder estatutario, una vez ejercido, completa las determinaciones de la Constitución. Ello no supone un ejercicio federal del poder constituyente, puesto que el Estado autonómico se constituye a partir de la «soberanía nacional del pueblo español» (art.1 CE) y no desde un pacto constitucional entre pueblos soberanos. Precisamente por ello, ese poder soberano que reside en la Nación española siempre podría recuperar esa fragmentación y reintegrarla a la plena unidad e indivisibilidad. 
Por otra parte, el principio autonómico (art. 137 CE) «refleja una concepción amplia y compleja del Estado, compuesto por una pluralidad de organizaciones de carácter territorial dotadas de autonomía» (..) que son «de distinto rango» en dos sentidos: creación y naturaleza. El principio dispositivo incide sobre ambos: 1) «frente a la autonomía municipal y provincial, el acceso de las nacionalidades y regiones a la autonomía aparece regulado en la Constitución de acuerdo con unos principios dispositivos que permiten que el régimen autonómico se adecue en cada caso a las peculiaridades y características de esas regiones y nacionalidades». (STC 16/1984, de 6 febrero, FJ 2); 2) Mientras la autonomía local ha sido concebida esencialmente como una "garantía institucional» de los municipios y provincias frente al legislador ordinario (estatal o autonómico), la autonomía de las CCAA se encuentra garantizada en el «bloque de la constitucionalidad», del que forman parte los Estatutos de Autonomía, y de ahí su vinculación al principio dispositivo por cuanto los titulares del derecho a la autonomía, al contrario de los entes locales, han participado en la configuración de su autonomía, que puede ser "cualitativamente superior a la administrativa".

Llegados a este punto, se examinan las manifestaciones del principio dispositivo: materiales, temporales, subjetivas. Si la esencia del mismo es que la la Constitución impone la necesidad de contar con esa capacidad de propuesta (iniciativa, voluntad) y de codecisión de las entidades territoriales para adoptar decisiones constitucionales que afecta a la estructura territorial, es claro que el principio dispositivo no está presente en todos los elementos de la estructura territorial, ni se manifiesta igual en todas las decisiones respecto de aquélla, ni lo hace siempre con la misma intensidad ni en la misma forma a través del tiempo.

Para conocer las manifestaciones materiales debe partirse de la citada STC 16/1984, donde el Tribunal Constitucional declaró que:

«el principio dispositivo [que] alcanza a materias como la denominación a adoptar, que podrá acomodarse a la tradición histórica; el procedimiento de acceso a la autonomía, que presenta diversas modalidades, como se desprende de los arts. 143, 144, 151, disposición adicional primera, disposiciones transitorias primera, segunda, cuarta y quinta de la $\mathrm{CE}$, competencias a asumir, como resulta de los artículos 148 y 149, entre otros, de la CE, e instituciones de los entes autonómicos, siempre dentro de los límites que la Constitución señala. Como consecuencia, y en virtud de las disposiciones constitucionales, el acceso a la autonomía de las nacionalidades y regiones se ha producido por vías diversas y se ha configurado en formas muy distintas de un caso a otro. Ello no obstante, y sin perjuicio del margen dejado a las peculiaridades y características de cada nacionalidad o región, la CE contiene una serie de preceptos y disposiciones referentes a la ordenación de este proceso de reestructuración territorial del Estado, de los 
que se excluye el principio dispositivo, fijando normas a las que los entes autonómicos así creados deben atenerse» (FJ 2).

Se puede afirmar que el principio dispositivo se manifiesta materialmente en dos elementos esenciales de la estructura territorial en su conjunto: la creación y delimitación de las entidades territoriales, y la distribución del poder entre éstas y las instancias centrales del Estado. $Y$ en varios elementos definitorios de su respectivo autogobierno, contenidos en su norma institucional básica, el Estatuto de Autonomía.

En cuanto a las manifestaciones temporales del principio dispositivo, el Consejo de Estado en su "Informe sobre modificaciones de la Constitución española» (16 de febrero de 2006), distingue dos. En el estado inicial o transitorio, aquél se expresa mediante la "potestad de impulsar la creación y organización de las Comunidades Autónomas» de acuerdo con los procedimientos establecidos en la Constitución. Y una vez terminada la división del territorio, se concreta en la "facultad de redefinir de manera indefinida el ámbito de su autonomía», que se atribuye a las CCAA mediante la reforma de los Estatutos, a las que corresponde «la facultad de proponer y codecidir la modificación de sus ámbitos competenciales» y alterar también, en cierto modo, el que queda en manos del Estado.

En ambos momentos, instauración y modificación, actúa el principio dispositivo. Sin embargo, debe tenerse en cuenta que las manifestaciones del principio son claramente distintas en cada momento pues distintos son los entes territoriales cuya voluntad se requiere, los aspectos de la estructura territorial sobre los que actúa, así como su eficacia real y actual.

Junto a las manifestaciones materiales y temporales, deben abordarse las manifestaciones subjetivas, es decir, las relativas a la identificación de las entidades territoriales a las que la Constitución atribuye la capacidad de propuesta y codecisión sobre determinados aspectos de la estructura territorial, cuestión que guarda estrecha relación con la titularidad y el contenido del derecho a la autonomía de las nacionalidades y regiones reconocido en el art. $2 \mathrm{CE}$, una disposición también original respecto de otras Constituciones federales y respecto de la Constitución de 1931, que no lo contemplaba.

En este punto, debe examinarse la titularidad y el ejercicio del derecho a la autonomía (art. 2 CE) con el propósito de esclarecer la relación entre ambos aspectos del derecho y el principio dispositivo.

Respecto a lo primero, el principio dispositivo se manifiesta no sólo en relación con la titularidad del derecho a la autonomía sino también con los sujetos del derecho de iniciativa autonómica, que como ha señalado la jurisprudencia 
constitucional no coinciden. Respecto a lo segundo, creo que el principio dispositivo permite dar un significado al derecho a la autonomía de las nacionalidades y regiones que no lo reduce a la mera iniciativa, ni a la posibilidad de convertirse en CCAA, ni a la conservación de la autonomía, confundiendo el derecho a la autonomía con la autonomía como principio estructural, es decir, como división vertical del poder asimilable al principio federal. A mi juicio, la capacidad decisiva que deben mantener los entes territoriales no sólo en la creación sino también en la modificación de la estructura territorial, exige que el derecho a la autonomía contenga una garantía de su contenido, así como una capacidad de disposición del autogobierno al que las nacionalidades y regiones aspiren en cada momento dentro del marco de la Constitución. Este significado del derecho a la autonomía es el que parece acogerse en las últimas reformas estatutarias. Así, la Ley Orgánica 5/2007, de 20 de abril, de reforma del Estatuto de Autonomía de Aragón, dispone en art. 1, (intitulado El autogobierno de Aragón): "Aragón, nacionalidad histórica, ejerce su autogobierno de acuerdo con el presente Estatuto, en el ejercicio del derecho a la autonomía que la Constitución reconoce y garantiza a toda nacionalidad.». Nótese que el precepto atribuye la titularidad del derecho a la autonomía a la «nacionalidad», y su ejercicio se traduce (valga la redundancia) en «ejercer su autogobierno».

\section{EL DESARROLLO DEL PRINCIPIO DISPOSITIVO EN EL PROCESO AUTONÓMICO}

Tras los primeros pasos en el proceso de reestructuración territorial del poder, se asentó pronto entre los partidos de ámbito estatal y en un sector de los constitucionalistas españoles la opinión de que el principio dispositivo tenía efectos distorsionadotes o disfuncionales para la construcción de un nuevo modelo de organización territorial, opinión que ha perdurado hasta nuestros días.

Los intentos de reducir la eficacia del principio dispositivo en sus diversas manifestaciones materiales y temporales se dieron en una primera etapa del proceso autonómico (instauración), mediante los Acuerdos autonómicos de 1981; y en una segunda etapa (modificación), con los pactos autonómicos de 1992. Tales intentos se llevaron a cabo utilizando diversos mecanismos políticos y jurídicos (una supuesta convención constitucional, las leyes del art.150.2 $\mathrm{CE}$ ), ajenos al principio dispositivo, y destinados a dirigir el proceso de descentralización política desde las instancias centrales con el propósito de concretar y «ultimar» el Título VIII mediante el acuerdo entre las dos grandes fuerzas políticas de ámbito estatal, y no desde la capacidad de iniciativa y de decisión de las 
instancias territoriales. Estos intentos supusieron una interpretación homogeneizadora del derecho a la autonomía, y un desplazamiento de la capacidad decisiva de los entes territoriales hacia otros poderes (Partidos, Gobierno), forzando el texto constitucional.

Los Acuerdos autonómicos de 1981 y 1992 fueron pues dos intentos de reducir la eficacia de un principio estructural básico de la Constitución mediante pactos políticos que evitaran una reforma constitucional. Aunque quizás lo más importante sea retener que aquellos intentos no consiguieron eliminar ese principio constitucional fundamental, que permaneció latente.

Ello quedó demostrado con los procesos de reforma estatutaria iniciados en el País Vasco y Cataluña (que no habían reformado sus Estatutos desde su aprobación), y que partían de dos iniciativas o propuestas que entrañaban un cambio sustancial de su respectivo marco jurídico-político, y suponían una alternativa al modelo territorial desarrollado a partir de la Constitución de 1978. Las dos iniciativas presentaban numerosas y profundas diferencias entre sí, pero ambas propuestas se basan, hasta cierto punto, en la idea de dotar a la nación de una nueva «norma institucional básica» que refunda la propia comunidad política, ya existente, como un sujeto propio que intenta autodeterminarse. Y quizás lo más importante, ambas iniciativas, como señala Muñoz Machado, se activaron a partir de la idea de «autodeterminación, refundada en principio dispositivo».

Las reformas estatutarias, encabezadas por el nuevo Estatuto de Autonomía de Cataluña de 2006 (EAC), han tratado de modificar la estructura territorial, o buena parte de ella, al amparo de la desconstitucionalización, intentando ampliar al máximo los efectos del principio dispositivo en el momento de modificación de la estructura territorial. Dichas reformas no son objeto de estudio en el presente trabajo, que se limita a examinarlas sólo como tentativa de maximizar el principio dispositivo.

La reforma del EAC pone a prueba la medida de la desconstitucionalización de la estructura del Estado y los límites del principio dispositivo porque habría aprovechado al máximo esta disponibilidad derivada de la desconstitucionalización utilizando todas las posibilidades imaginables, entre otras, su forma y contenido (que ha sido discutido por desbordar la materia estatutaria), o la función constitucional que pretende llevar a cabo en temas como la autoidentificación de la CA, el régimen lingüístico, la financiación, o la asunción de competencias.

Con las reformas estatutarias se ha iniciado lo que se ha llamado «segundo proceso autonómico», el cual ha reavivado el interminable debate político y jurídico sobre la estructura territorial y la cuestión nacional en España. La pretensión de una reforma del Estado Autonómico en su conjunto basada en una 
reforma estatutaria generalizada ha suscitado dudas, críticas y objeciones entre los constitucionalistas, que ponen en cuestión la conveniencia de emprender tal operación basándose en la desconstitucionalización y en el principio dispositivo.

El examen del desarrollo del principio dispositivo a través del proceso autonómico (y los intentos de reducir o maximizar su eficacia) permite concluir que aquél sigue siendo la principal característica del Estado Autonómico, como lo demuestra el hecho de que, implícita o explícitamente, se haya situado en el centro del debate jurídico-constitucional sobre las actuales reformas normativas (estatutarias o constitucionales) que afectan a la estructura territorial en España.

Pero dicho examen permite llegar a algunas conclusiones que tienen algo de paradójicas: en la fase de instauración de la nueva estructura territorial, la desconstitucionalización permitió una drástica eliminación de los efectos del principio dispositivo a través de mecanismos de naturaleza incierta que podrían ser vistos como una mutación constitucional, por cuanto contradicen el contenido de este principio estructural básico de la Constitución, tanto desde el punto de vista del procedimiento como del resultado. En la fase de modificación, en cambio, la desconstitucionalización permitiría una maximización de los efectos del principio dispositivo hasta llegar a una «desnaturalización» del mismo, que también puede ser vista como una mutación constitucional por cuanto las reformas estatutarias pretenderían modificar la Constitución sin acudir al procedimiento de reforma.

La reforma constitucional que fue planteada por el Gobierno simultáneamente a las reformas estatutarias puede ser entendida, según Rubio Llorente, como una respuesta a la necesidad de reflexionar sobre el significado del principio dispositivo tras veinticinco años de operación. El desarrollo de este principio estructural básico a través del proceso autonómico habría conducido, paradójicamente, a una propuesta de reforma constitucional que plantea la posibilidad de abandonarlo, al menos parcialmente.

\section{EL ABANDONO DEL PRINCIPIO DISPOSITIVO MEDIANTE LA REFORMA CONSTITUCIONAL}

Como se ha anunciado en la Introducción, la última parte del trabajo analiza el eventual abandono del principio dispositivo mediante una reforma constitucional y sus implicaciones.

En primer lugar se examina la propuesta de modificación constitucional contenida en el Acuerdo del Consejo de Ministros, de 4 de marzo de 2005, por el cual el Gobierno solicita del Consejo de Estado que emita un informe sobre la 
reforma constitucional propuesta por el Presidente del Gobierno en su discurso de investidura basada en cuatro puntos, uno de los cuales está destinado a «la recepción constitucional de la denominación oficial de las Comunidades Autónomas y de las Ciudades Autónomas». A continuación se estudia la respuesta a dicha consulta contenida en el «Informe sobre modificaciones de la Constitución española» aprobado por el Pleno del Consejo de Estado el 16 de febrero de 2006. El examen de los textos intenta verificar hasta qué punto y en qué manifestaciones el Acuerdo y el Informe contemplan la posibilidad de abandonar el principio dispositivo mediante una reforma constitucional, concluyendo que ninguno de los dos documentos plantea una efectiva eliminación de dicho principio, al menos tal como se concibe en este trabajo.

La importancia de la propuesta gubernamental reside en las implicaciones que tiene sobre el principio dispositivo, apreciación en la que coincidieron quienes opinaron sobre el contenido del Acuerdo, aunque con notables diferencias en cuanto a las consecuencias jurídicas que del mismo podrían derivarse. El texto del Acuerdo ha permitido sugerir que la incorporación de las CCAA a la Constitución podría tener una gran trascendencia para el Estado Autonómico, por cuanto pondría fin parcialmente a la llamada «desconstitucionalización», lo que a su vez afectaría a la eficacia del principio dispositivo. Pero se constatan profundas divergencias a la hora de prever las implicaciones que dicha modificación podría tener sobre otros aspectos de la actual estructura territorial, tal como se ha concretado a partir de la Constitución.

En cuanto al Informe del Consejo de Estado, éste consiste propiamente en un «informe» sobre modificaciones de la Constitución, y no en la elaboración de "propuestas de reforma constitucional», aunque incluya redacciones posibles de preceptos constitucionales «a efectos indicativos». A mi juicio tampoco el Consejo de Estado propone en su Informe el abandono del principio dispositivo aunque en el mismo esté subyacente una posición crítica hacia el mismo e incluso hacia su actual vigencia. Pero de las consideraciones del Informe respecto a las concretas modificaciones propuestas, así como las relativas a las «otras cuestiones» relacionadas con aquéllas, no se concluye que el Consejo de Estado haya «informado» favorablemente sobre una reforma constitucional que tenga por objetivo la eliminación del principio dispositivo.

Esta conclusión se desprende de un análisis del Capítulo IV del Informe, titulado «Inclusión de la denominación de las Comunidades Autónomas», donde se realizan importantes afirmaciones sobre el principio dispositivo, que demuestran dos cosas: a) que el Informe contempla la posibilidad de abandonar dicho principio, en su calidad de principio básico de la estructura territorial, pero no contiene una propuesta dirigida a su eliminación en una futura Cons- 
titución reformada; el Consejo de Estado no aboga por un «cierre» del modelo mediante la desaparición del principio dispositivo, que considera una operación no prevista en la propuesta de reforma constitucional del Gobierno, y además entrañaría la sustitución del actual modelo abierto que aún permanece en la Constitución; y b) que el Informe realiza propuestas de reforma respecto a la denominación de las CCAA y el mapa autonómico que disminuyen la eficacia del principio dispositivo, pero sin eliminarlo completamente.

Hechas las anteriores constataciones, se analizan finalmente las posibles vías para una eventual eliminación del principio dispositivo de la actual Constitución y las previsibles consecuencias constitucionales que se derivarían de ello, adentrándose así en un terreno más especulativo que interpretativo.

Se consideran las distintas alternativas constitucionales para alcanzar aquel objetivo, y las implicaciones que se derivarían de su realización. Son dos las vías que, de constitutione ferenda, se contemplan:

a) La modificación de los procedimientos de reforma de los Estatutos de Autonomía para reducir la capacidad de impulso y coparticipación en los mismos de las CCAA; dicha facultad podría verse drásticamente reducida dificultando las posibilidades de propuesta de reforma estatutaria de las CCAA (disminuyendo la facultad de propuesta de iniciativa o la facultad de iniciativa de reforma; constitucionalizando algunos aspectos de los procedimientos de reforma) o disminuyendo su capacidad decisoria en dichos procedimientos (con mayorías en las Cortes más cualificadas que las Leyes Orgánicas).

b) La conversión de las materias estatutarias, o de parte de ellas, en materias constitucionales, de manera que algunos elementos definidores de la autonomía de las CCAA sólo pudieran modificarse a través de una reforma constitucional. Ello implicaría un cambio radical que afectaría no sólo a la autonomía actualmente "garantizada" a las CCAA mediante la rigidez de sus Estatutos, sino al conjunto de la estructura territorial del Estado, tal como se encuentra regulada en la vigente Constitución. En palabras ya citadas del Consejo de Estado, tal reforma no supondría reducir la apertura del sistema sino el cambio del sistema: un cambio materialmente constitucional, que afectaría a la misma definición de la forma de Estado deliberadamente decidida por el constituyente. De ahí que la ejecución de una reforma constitucional con tales objetivos plantearía algunas cuestiones relativas al procedimiento de reforma constitucional que debería seguirse, y a los límites materiales del poder de reforma como poder constituido. Sobre ellas voy a realizar algunas consideraciones.

La primera es que una reforma constitucional que redujera drásticamente las actuales materias estatutarias (art. 147.2 CE), «modificando el contenido esencial 
o nuclear de los Estatutos», afectaría al derecho a la autonomía del art. $2 \mathrm{CE}$, y por ello debería realizarse a través del procedimiento del art. $168 \mathrm{CE}$. Tal como se ha expuesto, el derecho a la autonomía de las nacionalidades y regiones no es sólo el derecho a acceder a ésta sino que incluye una garantía de su contenido así como una capacidad de disposición del autogobierno en virtud del principio dispositivo. Todo ello se vería alterado si se sustrajera del Estatuto la capacidad de reconfigurar el autogobierno de cada Comunidad Autónoma, o si se quiere, la facultad de redefinir el ámbito de su autonomía. El principio autonómico constituye uno de los principios supremos del ordenamiento constitucional y, por lo tanto, opera como límite material a la propia revisión constitucional. Sin entrar ahora en la calificación dogmática que merece la reserva de determinadas materias al procedimiento de reforma constitucional previsto en el art. $168 \mathrm{CE}$, lo cierto es que éste y no el del art. $167 \mathrm{CE}$ es el procedimiento que debe seguir una propuesta de revisión que «afecte al Título Preliminar» de la Constitución, donde se contienen las decisiones políticas fundamentales, entre las cuales se encuentra la relativa a la estructura territorial, expresada en los principios del art. 2 CE.

La segunda cuestión que suscitaría una reforma constitucional como la descrita obligaría a plantearse si, aun utilizando el procedimiento previsto en el art. $168 \mathrm{CE}$, el poder de reforma se vería sometido a algún tipo de límites. En principio, dado que aquel precepto permite la «revisión total» de la Constitución, y en consecuencia no se establecen «cláusulas de intangibilidad», nada impediría que mediante dicho procedimiento se eliminara total o parcialmente la reserva estatutaria y se modificara sustancialmente el derecho a la autonomía de las nacionalidades y regiones del art. $2 \mathrm{CE}$. Desde luego, no tendría los mismos efectos la constitucionalización de la distribución de competencias [art. 147.2 d) $\mathrm{CE}$, que la constitucionalización de otras materias reservadas a los Estatutos, contempladas en ese mismo precepto constitucional [art. 147.2 a), b), c) CE].

La primera afectaría esencialmente al principio dispositivo, pero no eliminaría (si bien podría reducirla) la autonomía de las CCAA, pues sus competencias quedarían determinadas y garantizadas en el mismo texto constitucional, como ocurre en los sistemas federales. La segunda, en cambio, afectaría a la capacidad de configuración política de cada Comunidad Autónoma (de «constitución interna»), propia de las entidades políticas territoriales en todos los Estados compuestos, ya que esa configuración sería decidida por la Constitución o bien por leyes estatales, tal como ocurre con los entes locales, que sólo gozan de una "garantía institucional».

Se podría argumentar entonces que la autonomía, como potestad de autoorganización política de las CCAA, es intangible incluso para el poder agravado de reforma. O que una reforma constitucional de esos aspectos del derecho a la 
autonomía provocaría una alteración fundamental del orden constitucional vigente, dando lugar a un nuevo orden que ya no sería propiamente el de la Constitución actual. Incluso podría sostenerse que el poder constituyente originario, al aceptar voluntariamente su fragmentación entregando parte de las regulaciones que le competen a un poder subordinado (el poder estatutario), se autolimitó. Y que si bien, como poder soberano, siempre podría recuperar esa fragmentación y reintegrarla a la plena unidad e indivisibilidad, ello resultaría difícil ya que la desarticulación del sistema de autonomías, mediante decisiones constituyentes revocatorias de lo establecido en los Estatutos, supondría una convulsión política y jurídica de enorme envergadura (Muñoz Machado). Dejo simplemente planteada esta segunda cuestión, que pone de manifiesto hasta qué punto sería compleja una reforma constitucional destinada a la supresión del principio dispositivo.

La tercera cuestión está vinculada a la anterior y plantea la posibilidad de superar algunos de los problemas que suscitaría esa eventual reforma constitucional destinada a abandonar el principio dispositivo. La eliminación de este principio estructural de nuestro ordenamiento, como se ha dicho, supondría la sustitución de la actual estructura territorial por otra en la que las CCAA perderían su "capacidad decisiva» no sólo sobre la configuración de su autogobierno sino sobre el conjunto de la organización territorial del Estado. De constitutione ferenda, se podría pensar en compensar esa pérdida mediante su participación en el proceso de reforma constitucional, que actualmente se limita a la facultad de iniciativa (art. $166 \mathrm{CE}$ ), por supuesto, siempre que la reforma no se planteara como un retorno al unitarismo sino más bien como un paso hacia el federalismo. Ello exigiría que la propuesta de reforma constitucional incluyera una modificación de los procedimientos de reforma constitucional dirigida a asegurar la intervención decisiva, junto a las instituciones generales o centrales (las Cortes Generales), de las instituciones autonómicas (Asambleas legislativas de las CCAA).

Esta reforma constitucional para modificar los procedimientos de reforma constitucional en un sentido "federal» ha sido sugerida en Italia, pero también en nuestro país. Según Cruz Villalón, la refundación del actual Estado a través de una Constitución federal, que supondría una revisión total, tendría una dimensión procesal que exigiría una corresponsabilidad constitucional de las CCAA. $Y$ este proceso de reforma podría imaginarse en dos fases: en una primera se incorporaría la presencia de los territorios en el procedimiento de reforma, y en una segunda se daría lugar a la Constitución federal. En un sentido similar entiendo que se pronuncia De Cabo Martín, quien sostiene que la conversión del Estado actual en un Estado federal no cabría a través de la reforma constitucio- 
nal. Y ello porque se trataría no ya de la creación sino del reconocimiento de la existencia de otros sujetos jurídico-políticos y, por consiguiente, no sería aceptable su exclusión del proceso de conformación del nuevo Estado constitucional. Ese proceso incluiría una primera fase de reconocimiento de esos sujetos jurídico-políticos y una segunda en la que, actuando como tales, como sujetos con capacidad para autodeterminarse y desde esa libertad, intervinieran en la configuración del nuevo pacto - federal — constitucional.

Éstas son pues algunas de las cuestiones que plantearía una reforma constitucional destinada a eliminar el principio dispositivo en tanto que principio estructural básico del Estado Autonómico. Por supuesto, esa eventual reforma suscitaría otras cuestiones de carácter sustantivo, en concreto, las consecuencias jurídicas y políticas que entrañaría la sustitución del sistema abierto y flexible que hoy tenemos por otro que probablemente no ofrecería la misma capacidad de adaptación a la «realidad constitucional» española. El propósito de este trabajo no es otro que el de someterlas a discusión entre la comunidad científica y contribuir así al debate constitucional que hoy tiene planteado nuestro país.

\section{Title}

The «Principio dispositivo» in the Autonomic State

\section{Resumen}

España vive hoy inmersa en un proceso de reformas de su organización territorial. En esta trabajo se sostiene que la clave del Estado Autonómico radica en el llamado principio dispositivo, la singularidad más destacada de nuestra Carta Magna, hasta el punto de poder considerarse la aportación más original de los constituyentes de 1978 al constitucionalismo universal. Dicho principio se incorporó a la Constitución mediante un compromiso constitucional «apócrifo», inspirado en el Estado integral de la II Republica, y confiere a las entidades territoriales una capacidad para proponer y codecidir la creación y modificación de su autogobierno. A pesar de su trascendencia, el principio dispositivo no ha sido hasta hoy objeto de especial atención por parte de nuestro Derecho Público, probablemente por considerar que ya había agotado su vigencia una vez instaurado el modelo autonómico. Sin embargo, las reformas estatutarias iniciadas con el nuevo Estatuto catalán de 2006 han reavivado el debate sobre la «apertura» del modelo, demostrando que el principio dispositivo se mantiene vivo en nuestra Constitución. Por su parte, la propuesta de reforma constitucional del Gobierno y el Informe del Consejo de Estado apuntan la posibilidad 
de abandonarlo, poniendo fin a la "desconstitucionalización» de la forma de Estado para lograr el «cierre» del modelo. Ahora bien, la naturaleza y las características del principio dispositivo, que se abordan en este trabajo, ponen de manifiesto los problemas que suscitaría una reforma constitucional que pretendiera eliminarlo, y las consecuencias jurídicas y políticas que ello entrañaría para nuestro sistema constitucional.

\begin{abstract}
Nowadays Spain is living through an overhaul of its territorial structure. In this paper we argue that the key of the so called Autonomic State is the "principio dipsositivo", the most singular feature of the Spanish Constitution, considered the most original contribution of the founding fathers to the constitutionalism. This principle was included in the Constitution through a "false» constitutional agreement inspired at the "Estado integral» of the II Republic, and it confers to the territorial units the capability to propose and to co-decide the creation and the modification of its self-government. Notwhithstanding its relevance, the Public Law Scholars have not payed attention, until now, to this principle, probably because they don't consider it not to be in force once the Spanish structure was established. Nevertheless, the process of reforms of several Statutes of Autonomy, lead by the new Catalan Statute of 2006, has revived the debate on the "openness» of the Spanish model, showing that this principle is still alive in our Constitution. On the other hand, the governmental proposal of constitutional amendment and the Report of the Council of State point at the possibility of removing this principle, in order to «shut down» the system. Yet, the nature and character of the "principio autonómico", addressed in this paper, shows the problems that would arise from such an amendment, and also demonstrate the political and legal consequences it would entail for the Spanish constitutional system.
\end{abstract}

\title{
Palabras clave
}

Principio dispositivo, desconstitucionalización, Estado autonómico, Constitución, proceso autonómico, Estatuto de Autonomía, reforma estatutaria, reforma constitucional

\section{Key words}

"Principio dispositivo», deconstitutionalization, Autonomic State, Spanish Constitution, process of devolution, Statute of Autonomy, Constitucional reform 


\section{Summary}

Introduction. I. The inclusion of the "principio dispositivo" in the Spanish Constitution of 1978 and the precedent of the II Republic. II. The "principio dispositivo" and «deconstitutionalization». III. The "principio dispositivo" as a constitutional principle. IV. The development of the "principio dispositivo" throughout the process of devolution. V. The withdrawal of the "principio dispositivo" through the Constitucional reform. 